\title{
Multifunctionality of coatings made of polymer modified cementitious mortar
}

\author{
Barbara Francke ${ }^{1, *}$, Ewa Sudot ${ }^{1}$, and Damian Wojnowski ${ }^{1}$ \\ ${ }^{1}$ Building Research Institute, Filtrowa 1, 00-611 Warsaw, Poland
}

\begin{abstract}
The paper analyses durability of typical waterproofing coatings and assesses their influence on concrete surface protection in their different functions - as carbonation resistance and resistance to chemicals. For this purpose, a polymer modified cementitious mortar product was chosen for tests, one representative in its class and with properties typical for this group of materials. The tests were performed both using standard methods and methods of own design. The results presented in this article confirm that it is possible to develop a composition of a polymer modified cementitious mortar product which ensures creation of an effective and durable coating which serves as a waterproofing layer, chemical protection layer - in a limited scope, naturally - and surface protection against concrete carbonation.
\end{abstract}

\section{Introduction}

In recent years work is being done in order to extend functionality of currently used construction products to reduce costs of construction and to use the available technology as widely as possible. This also applies to polymer cement products intended to be used as coatings. In the light of standardising efforts, these products are the subject of interest of several different technical committees, active both in the construction sector as well as the chemistry sector. Such a thematic division usually leads to differences in approach regarding assessment of the products' performance characteristics, even though in real life conditions their function is very similar. The products are evaluated differently if the manufacturer declares a waterproofing function than when they are used as surface protection of concrete, despite the fact that in service, these functions greatly overlap. Products intended for surface protection of concrete[1] are included in the series of standards EN 1504, and if the surface protection is applied in an environment where water or moisture is present, assessment of the same coatings is based on standard EN 14891 or ETAG: 005[2] and/or ETAG 022[3]. Manufacturers often declare dual function of their materials, which forces the necessity to perform multiple tests of the same characteristic, evaluated using different methods.

\section{Experiment}

\footnotetext{
* Corresponding author: b.francke@itb.pl
}

\subsection{Scope}

The Building Research Institute in Warsaw (Poland) has undertaken research aimed at confirming that it is possible to develop a composition of a polymer modified cementitious mortar product in a way which would allow the coating made with its use to perform functions of waterproofing and chemical protection as well as protect the concrete substrate against carbonation. The results of the work, described in this article, do not exhaust the topic, presenting only selected aspects of the problem.

\subsection{Materials and test methods}

After initial elimination tests performed on different products in the same group, we chose a polymer modified cementitious mortar product possessing technical characteristics which are common for the represented material group, in its class. This product consists of two components:

- the first one is dry mixture with bulk density about $1,85 \mathrm{~g} / \mathrm{cm}^{3}$ consists of portland cement (CEM I), quartz sand and additives,

- the second one is emulsion with density about $1,0 \mathrm{~g} / \mathrm{cm}^{3}$, containing polymer synthetic resins and additional constituents.

These two components have to be mixed in weight proportion 3:1 (i.e. dry component : wet component). The coating made of this product chosen for further research has the following characteristics: 
- low water absorption after 24-hours of total immersion, equal to c. $4.3 \%$, (according to PN-EN ISO 62:2008)

- watertightness (after 28 days of curing) of $0.7 \mathrm{MPa}$, if the water pressure acted from the side of coating application, and $0.5 \mathrm{MPa}$ when water pressure acted on the opposite side (according to ZUAT$15 /$ IV.13./2002[4]), the coating's watertightness is very high for both tested options, which is typical for this material group,

- after 3 days of curing, the coating's watertightness is lower, at $0.5 \mathrm{MPa}$, when water pressure acted from the side of coating application. It was interesting to notice that after the first three days of curing, the coating applied on the side of water action achieves more than $50 \%$ of its final water resistance.

- bond strength of the coating applied on different substrates varies, and even on a substrate with low strength parameters, such as plasterboard, bond strength of coating made of polymer modified cementitious mortar product is higher than the strength of the substrate itself (fig. 1) and failure consists of loss of integrity in the substrate.

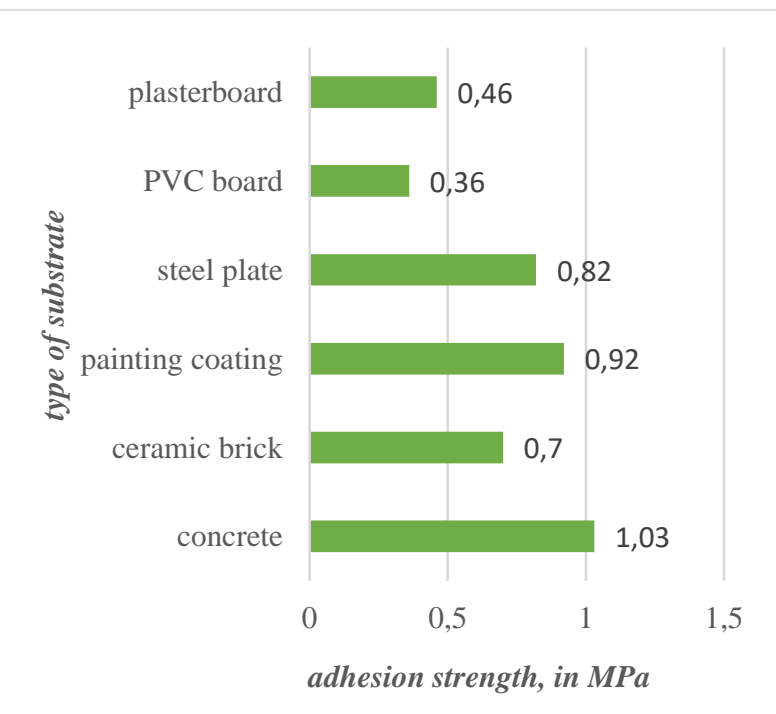

Fig. 1. Comparison of bond strength on different substrates for the representative coating

- the coating applied on concrete, is resistant to static loads of $5 \mathrm{~kg}, 10 \mathrm{~kg}, 15 \mathrm{~kg}, 20 \mathrm{~kg}$ without losing watertightness after application of the above load, in tests carried out in accordance with ZUAT-15/IV.13/2002[4].

The presented tests were performed both using standard methodology and methods of own design. The detailed reference of the applied test methods together with the analysis of the obtained results are presented in the next sections of the article.

\subsection{Results and discussion}

\subsubsection{Durability of mechanical properties of coating for different application variants}

The mechanical properties of the coating were assessed in accordance with rules set out for different functions, i.e. for waterproofing function - according to ZUAT-
15/IV.13/2002 and PN-EN 14891:2012, and for concrete surface protection - according to standard PN-EN 1504$2: 2006$. Due to the above, these tests were performed at different loads, using different test methods. In addition, the product was used at different performance conditions, both for the film cut out from the coating as well as coating applied on concrete substrate. The results of the tests are as follows:

$\checkmark \quad$ for the coating in the form of free film made with product usage $3.5 \mathrm{~kg} / \mathrm{m}^{2}$ without reinforcement, maximum tensile stress is very low, equal to $0.35 \mathrm{MPa}$, with corresponding elongation $27 \%$. Such tensile tests have been made in accordance with PN-EN ISO-527-1,3:1998 with a very low constant separating speed for the grips of $0.5 \mathrm{~mm} / \mathrm{min}$. Both these values rise considerably for a coating made with the use of a higher product amount, $4.5 \mathrm{~kg} / \mathrm{m}^{2}$, and with inside reinforcement by fleece with mass per unit area $50 \mathrm{~g} / \mathrm{m}^{2}$. The samples which have been also tested in the form of free film, reach levels of 1.33 $\mathrm{MPa}$ and $71 \%$ respectively.

$\checkmark \quad$ for the coating without any reinforcement applied to a concrete substrate using $3.5 \mathrm{~kg} / \mathrm{m}^{2}$ of the product, subjected to tension according to the test methodology set out in PN-EN 14891:2012 at a temperature of $23^{\circ} \mathrm{C}$, the first failure of the product appears at an elongation of $1.16 \mathrm{~mm}$. For the coating with inside reinforcement by fleece with mass per unit area $50 \mathrm{~g} / \mathrm{m}^{2}$ and made with the use of $4.5 \mathrm{~kg} / \mathrm{m}^{2}$ of the product on concrete substrate, tested under the same load, cracks appears at elongation of $1.73 \mathrm{~mm}$. At low temperatures, i.e. $-5^{\circ} \mathrm{C}$, the same coating has significantly reduced properties. In the version without reinforcement, on a concrete substrate and made with the use of $3.5 \mathrm{~kg} / \mathrm{m}^{2}$ of product, cracks appears at an elongation of $0.31 \mathrm{~mm}$, while for coating's samples with inside reinforcement by fleece with mass per unit area $50 \mathrm{~g} / \mathrm{m}^{2}$ and made with the use of $4.5 \mathrm{~kg} / \mathrm{m}^{2}$ of the product on concrete substrate, crack at an elongation of $0.40 \mathrm{~mm}$.

$\checkmark \quad$ according to standard PN-EN 1504-2:2006, the ability to cover cracks for the coating made on concrete with product consumption of $4.5 \mathrm{~kg} / \mathrm{m}^{2}$ may be classified as A3 at a temperature of $20^{\circ} \mathrm{C}$ and class $\mathrm{A} 2$ at the temperature of $-5^{\circ} \mathrm{C}$. Similarly, the coating reinforced with fleece with mass per unit area $50 \mathrm{~g} / \mathrm{m}^{2}$ and made with the use of $4.5 \mathrm{~kg} / \mathrm{m}^{2}$ of the product may be classified as A3 at a temperature of $20^{\circ} \mathrm{C}$ and as $\mathrm{A} 3$ at a temperature of $-5^{\circ} \mathrm{C}$.

The test results indicate that, from the point of view of mechanical properties, only the correct choice of the thickness of coating and use of a reinforcement may decide about the usage of the polymer - cement coating, both in the waterproofing function as well as concrete surface protection.

\subsubsection{Durability of the coating depending on variable environmental influence}

Artificial weathering was simulated in the laboratory in the following scope:

- low temperatures: in two variants, i.e. for waterproofing applications - according to ZUAT- 
15/IV.13/2002 and for concrete surface protection application - according to standard PN-EN 1504-2:2006, which is in the presence of de-icing salt,

- elevated temperatures and water, according to rules of assessment for waterproofing coatings - in conditions of combination of UV radiation, elevated temperature and water, and for concrete surface protection - in conditions including periodic storm effect.

Simulation of weather effects indicates proper behaviour of the polymer - cement coating under low temperatures in the test carried out according to methodology intended for assessment of waterproofing solutions, i.e. according to ZUAT-15/IV.13/2002. Frost does not cause a reduction of the coating's performance characteristic regarding watertightness, while bond strength with the substrate was only slightly decreased (from 1.03 MPa to $0.76 \mathrm{MPa}$ ). Unfortunately, a greater decrease in bond strength can be noted in the case of simultaneous influence of freezing temperatures and presence of sodium chloride solutions, which is the test method prescribed in standard PN-EN 1504-2:2006 for assessing concrete surface protection products. The obtained value of adhesion after the influence of these factors in this case was $0.6 \mathrm{MPa}$, but after taking into account uncertainty, it is close to the value required in standard PN-EN 1504-2:2006 for systems with crack properties or elastic ones, without trafficking. Decrease in adhesion determined based on results obtained from both the quoted tests is comparable and within measurement error for variable influence of freezing temperatures and moisture. These factors typically do not cause a significant reduction of performance characteristic of polymer-cement coatings as regards bond strength with the substrate. No significant adhesion reduction is noted even if the freezing temperatures and moisture are active in the presence of sodium chloride solution. The tests results are presented in diagram form in fig. 2.

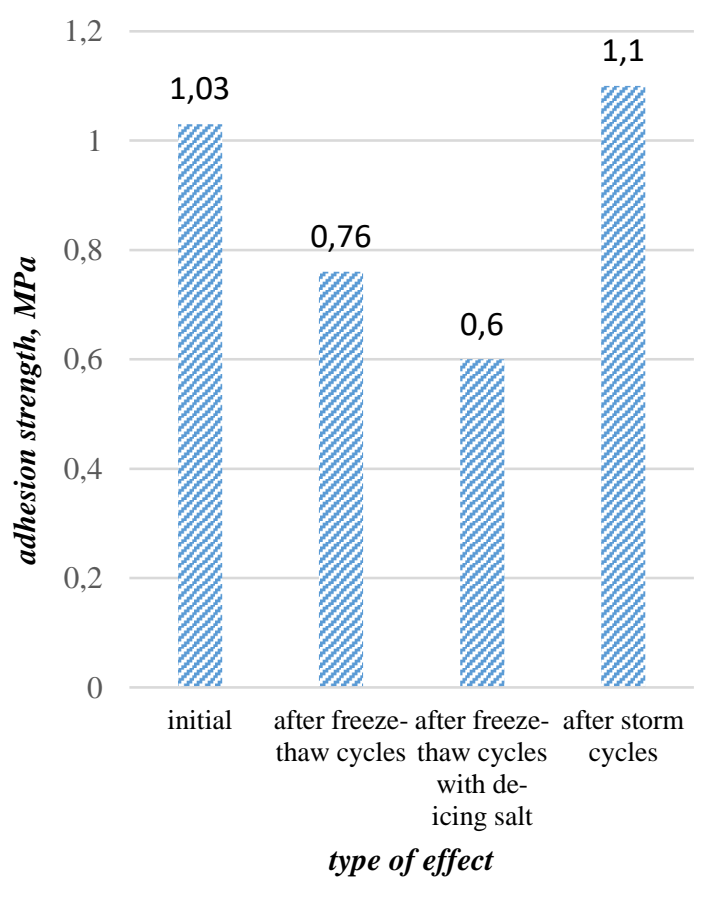

Fig. 2. Results of adhesion strength with concrete substrate after simulated weather effects, MPa
The effect of combined influence of UV radiation, elevated temperature and water is an increase in tensile stress of $82.9 \%$, with a small reduction in elongation $11.1 \%$, which allows to assume that in the event of being subjected to this kind of load the coating will retain its performance characteristics (fig. 3). It should be noted that the tests of mechanical properties describing the behaviour of the coating under ageing media were done at a very low speed $-0.5 \mathrm{~mm} / \mathrm{min}$, i.e. loads uncommon for the assessed coating, generating considerable stress inside the structure.

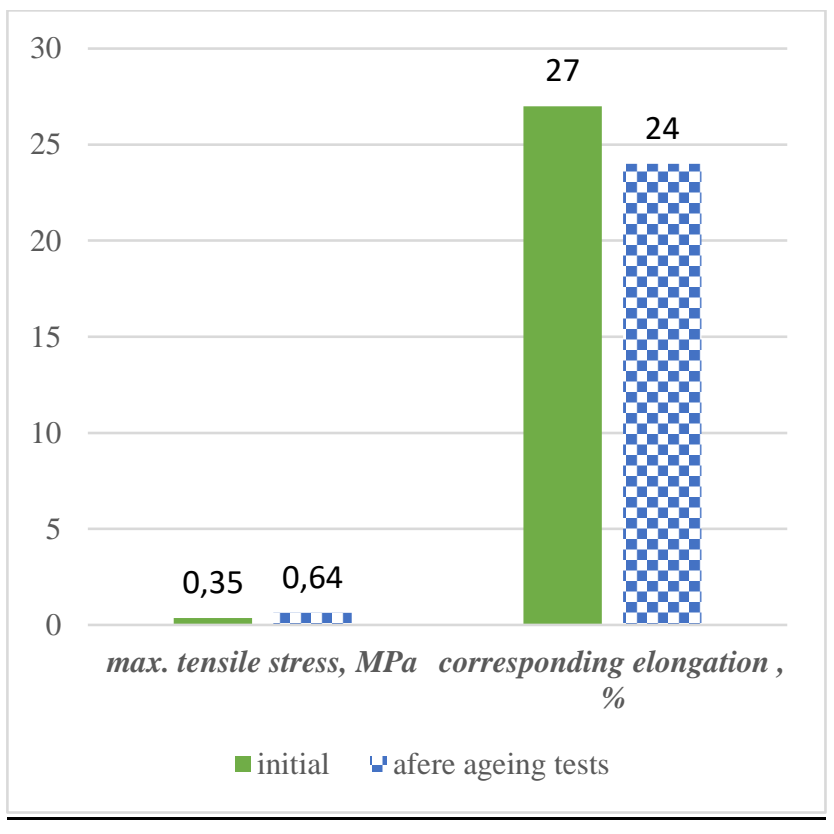

Fig. 3. Mechanical tensile properties of a new coating and after artificial weathering with combined influence of UV radiation, temperature and water

The assessment of the coating in conditions of periodic storm effect, expressed as adhesive strength to the substrate, is also positive, as no value decrease tendency was recorded in this case either (fig. 2). As can be inferred from the above analysis, tests performed using different methodologies, but reflecting similar service weather conditions, yield comparable results.

\subsubsection{Durability of the coating under influence of chemical solutions in the presence of water}

A coating's water absorption is one of the properties which has a significant influence on its durability. Assessed after 24-hour immersion in liquid, this property may only be used as comparative value, and the possibility should be taken into account that dampness will rise further if the product continues to perform under effects of water and moisture. Presence of chemicals may be an additional catalyst accelerating absorption. This article describes behaviour of coatings which serve as waterproofing and chemical protection in swimming pools disinfected with sodium hypochlorite, as well as in certain selected industries: car industry - influence of gasoline, and food industry - influence of malic acid, 
acetic acid and lactic acid. It was assumed that the basic requirement which the product needs to meet in order to be used for chemical protection against a specific agent is lack of mechanical damage of the coating after 28 days immersion in liquid chemicals, which can be assessed through visual inspection of samples after the completed test cycle. Further assessment depends on the assumptions in the test standard. In this case tests of coating adhesion, mass or elongation seem to be relevant. It was assumed that decrease in the coating's adhesion or relative elongation of over $20 \%$ were unacceptable.

As a result of keeping the coating for 28 days in sodium hypochlorite solution, where the concentration of free chlorine was $0.6 \mathrm{mg} / \mathrm{l}$ or $1.0 \mathrm{mg} / \mathrm{l}$, an increase of mass was recorded directly after removing the coating from the liquid, and subsequently a decrease of mass after drying, with increase of maximum stress and decrease of elongation (when applying extension with a speed at 0.5 $\mathrm{mm} / \mathrm{min}$ ). The decrease in characteristics do not disqualify the coating in the discussed application. It can be concluded that the polymer - cement coating may successfully perform two functions in a pool: waterproofing and chemical protection. The described results are illustrated in fig. 4 and 5.

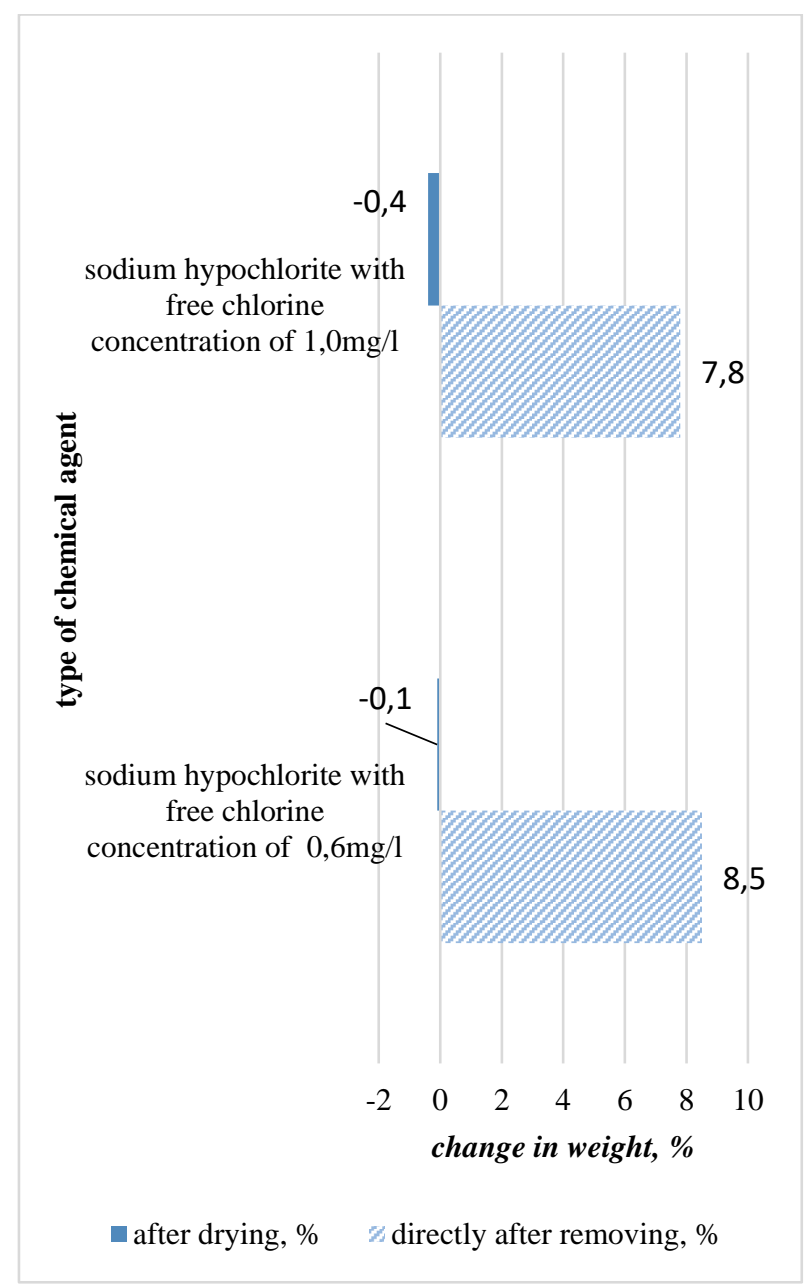

Fig. 4. Change of sample mass after 28 days of subjecting to the influence of sodium hypochlorite

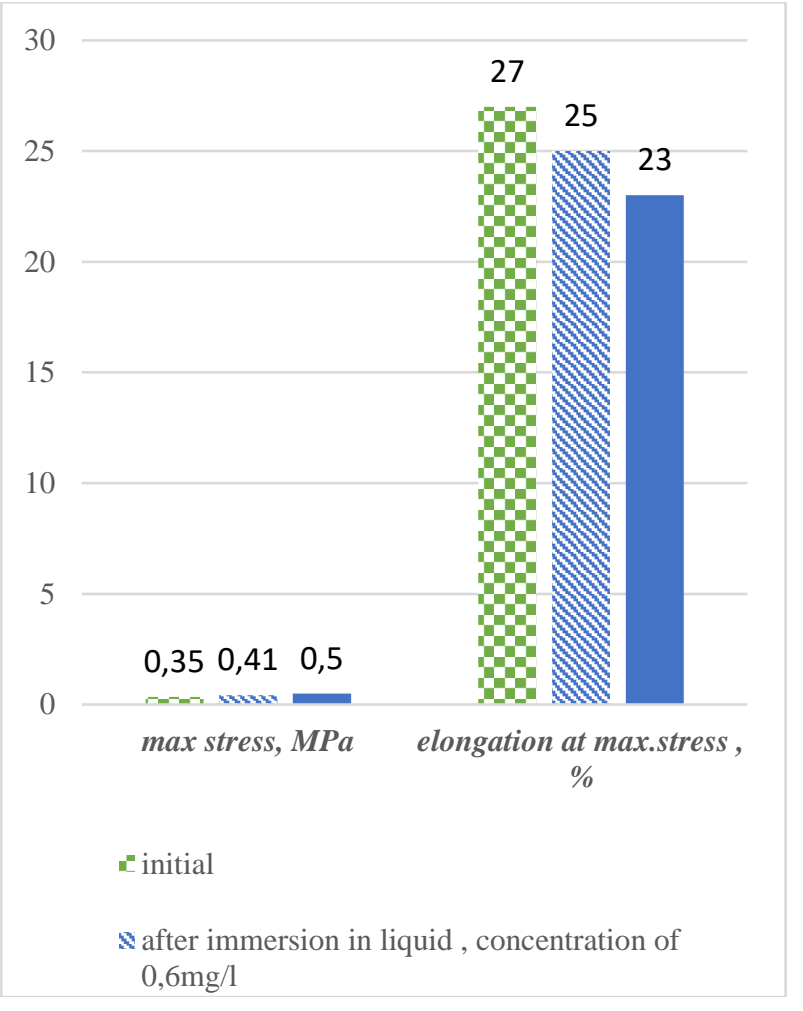

Fig. 5. Mechanical properties in tensile testing of a new coating and one after 28-day immersion in sodium hypochlorite

The coating's resistance to the influence of sodium hypochlorite is unfortunately not coupled with resistance to gasoline, as the coating decomposes during immersion in this test substance. In the case of malic acid at both $2 \%$ and 5\% concentration, the coating was completely damaged during immersion in the solution, which precludes further assessment of changes in mechanical properties.

In the other cases, changes in stress and elongation in the coating were recorded ( fig. 6 and 7), after immersion in: - $2 \%$ lactic acid: stress increase of $8.6 \%$, elongation decrease of $11.1 \%$,

- 5\% lactic acid: stress decrease of $71.4 \%$, elongation decrease of $44.4 \%$,

- $2 \%$ acetic acid: stress increase of $25.7 \%$, no change in elongation. 


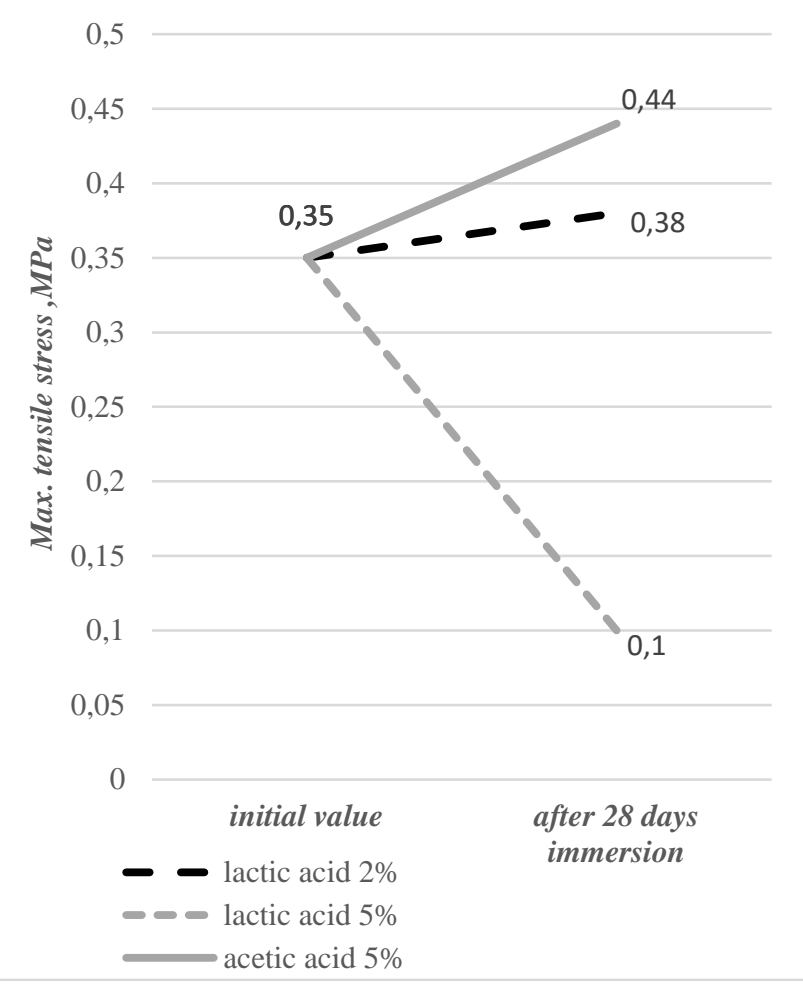

Fig. 6. Change of maximum tensile stress after 28 days of subjecting to the influence of chemical solutions

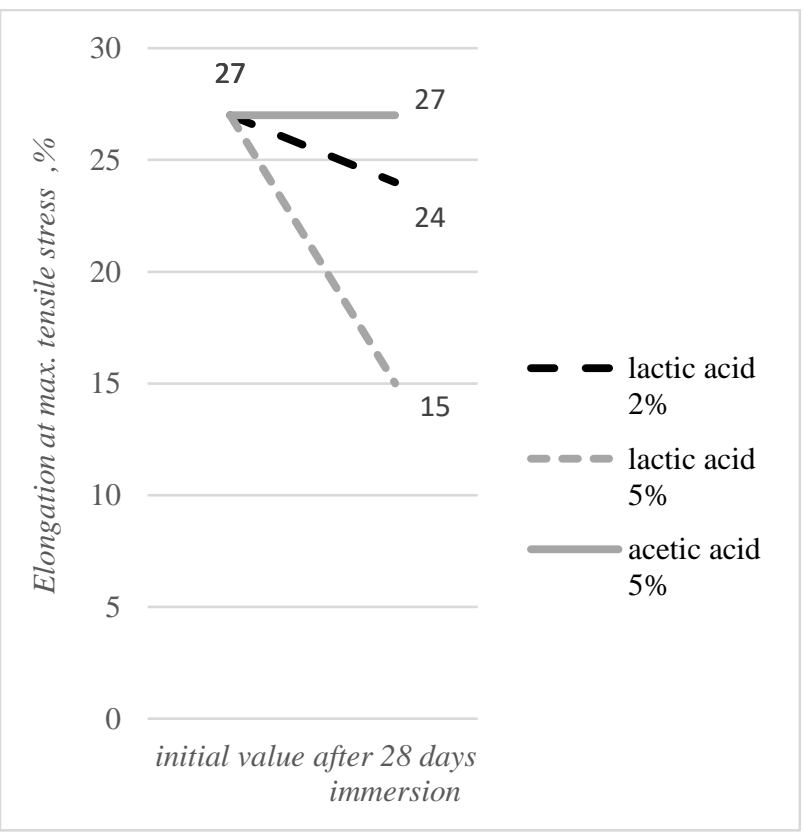

Fig. 7. Change of elongation at maximum tensile stress after 28 days of subjecting to the influence of chemical solutions

The obtained results indicate that a rise in lactic acid concentration from $2 \%$ to $5 \%$ cause disqualification of coating from use. In the case of acetic acid with $2 \%$ concentration, the increase of stress in the coating does not affect its elasticity, which is apparent due to the fact that it maintains the same elongation values after immersion in that solution. Evaluation of the changes in sample mass after the application of aggressive liquid agents shows that the processes taking place within their structure are not only reactions related to the chemical, but are intensified by absorption. For this reason, separating these two effects and evaluating the chemical agent in isolation is only possible after drying the coating completely. Using this assumption, the following effects of chemical agent influence were determined:

- after application of $2 \%$ lactic acid - $11.9 \%$ decrease in sample mass,

- after application of 5\% lactic acid $-15.0 \%$ decrease in sample mass,

- after application of $2 \%$ acetic acid - $14.5 \%$ decrease in sample mass.

In the case of $2 \%$ and $5 \%$ malic acid there was a considerable increase in the sample moisture content. A reduction of mass following drying the sample after application of $2 \%$ and $5 \%$ malic acid was: $15.1 \%$ and $13.7 \%$ respectively, while the increase of mass directly after removal from the liquid agent was: $77.0 \%$ and $81.5 \%$ respectively. This phenomenon leads to cracking of the coating after it is dried. It is evident that the malic acid in this case serves as catalyst for chemical reactions within the coating, contributing to faster water absorption, and destruction of the coating layer as as a result. Figure 8 shows variable rate of increase in dampness of the coating immersed in different chemical solutions, over the same time and with the same environment conditions.

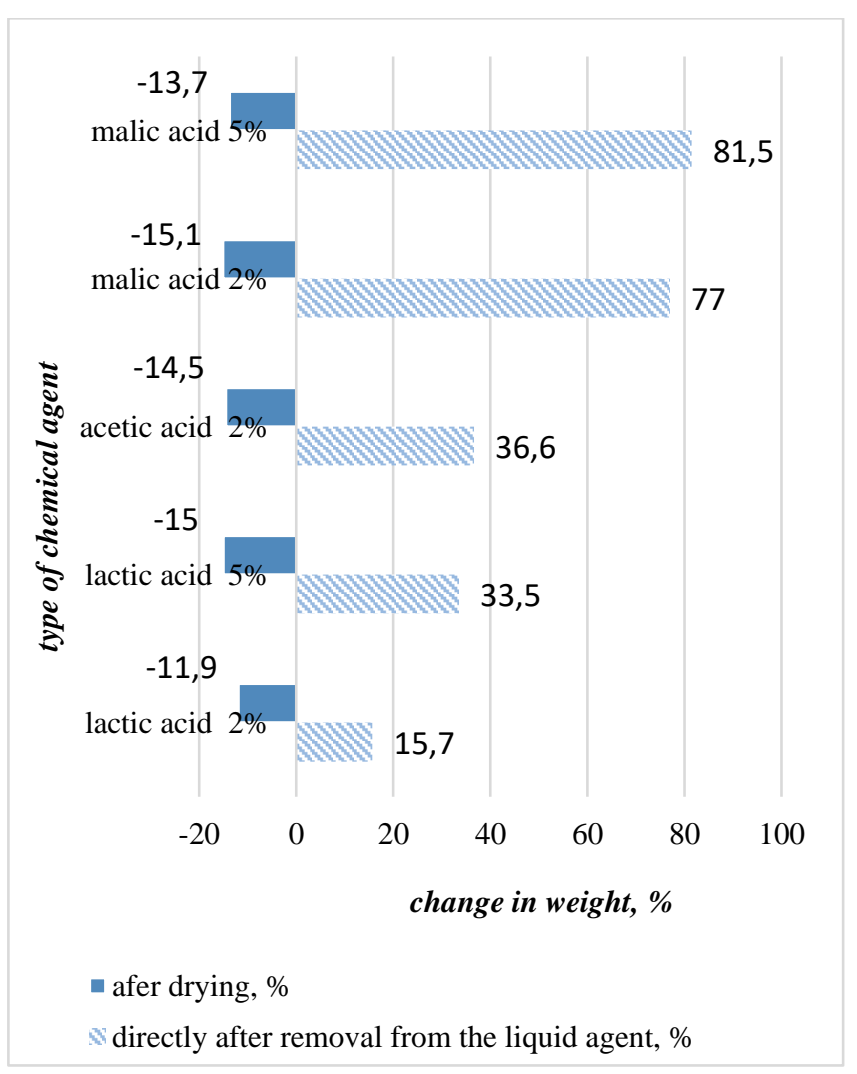

Fig. 8. Change in sample weight after 28 days of immersion in liquid chemicals

\subsubsection{Assessment of the coating's function in the category of protection against carbonation}

The analysed coating does not provide a water vapour barrier, as its $\mathrm{s}_{\mathrm{d}}$ value is $2.78 \mathrm{~m}$, which according to PN- 
EN 1504-2:2006 allows to include it in class I, described as "water vapour permeable"; at the same time in tests of carbon dioxide permeability it can be evaluated as effective barrier against carbonation. The carbon dioxide permeability $\left(\mathrm{s}_{\mathrm{d}}\right)$ resulting from the test was $95 \mathrm{~m}$, which is higher than $50 \mathrm{~m}$ (fig. 9). Such a high value of diffusion resistance to carbon dioxide, with simultaneous permeability of water vapour confirms the usefulness of the waterproofing coating as a product used for concrete protection against carbonation.

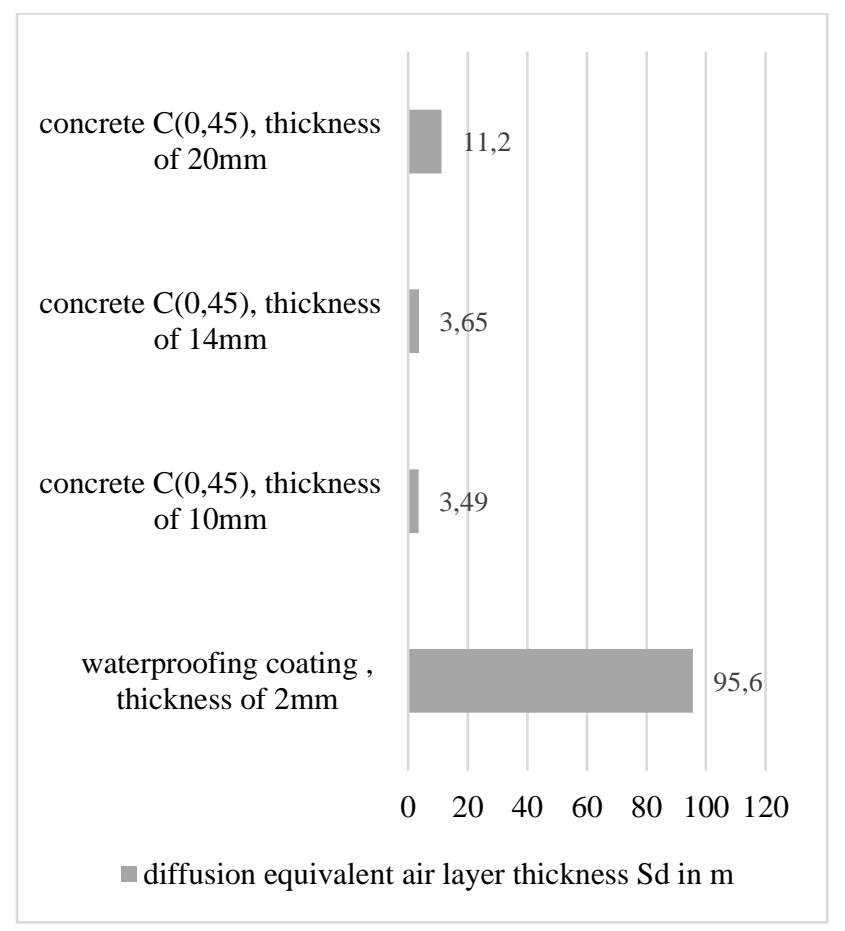

Fig. 9. Diffusion equivalent air layer thickness $S_{d}$ in $m$, for different test variants in the test of permeability of carbon dioxide

It may be assumed that thickness of concrete cover which would provide diffusion resistance $S_{d}$ equivalent to that of a surface protected with a $2 \mathrm{~mm}$ coating made of the representative analysed product would have to be $\mathrm{c} .16 \mathrm{~cm}$ thick. However, lack of homogeneity of concrete and lack of proportional relation between thickness and diffusion resistance obtained in tests for different concrete thickness allows to estimate the above value only roughly, without a clear answer in that regard. The resistance to chlorides penetrating the coating is additional confirmation that the coating is useful as concrete surface protection.

\section{Conclusion}

The test results discussed in this article suggest the following conclusions:

- $\quad$ such polymer- cement products exist which ensures creation of an effective and durable coating successfully performing functions of: waterproofing, chemical protection - in a limited scope, naturally - and surface protection against concrete carbonation.
- $\quad$ in all of these applications there are certain restrictions resulting from specific features of particular products and related to their performance characteristics.

The paper was prepared within the statutory research work at ITB (Warsaw, Poland) ${ }^{\circ}$ NZM-053/2017 and with the technical support of Wojciech Zięba, Artur Kupisz and Marcin Kupisz

\section{References}

1. L. Czarnecki Lech, P. Łukowski, A.Garbacz. 2017. „Naprawa i ochrona konstrukcji z betonu. Komentarz do PN-EN 1504". Warszawa. Wydawnictwo naukowe PWN SA

2. Etag 005 Guideline for European Technical Approval of liquid applied waterproofing kit, Part, European Organisation for Technical Approvals (2004)

3. Etag 022 Guideline for European Technical Approval of Watertight covering kits for wet room floors and or walls Part 1, European Organisation for Technical Approvals (2007)

4. B.Francke ,ZUAT-15/IV.13/2002 - Wyroby zwierające cement przeznaczone do wykonywania powłok hydroizolacyjnych, ITB Warszawa 